\title{
Live weight, carcass ultrasound images, and visual scores in Angus cattle under feeding regimes in Brazil
}

\author{
Luís Fernando Batista Pinto • \\ Jaime Urdapilleta Tarouco • Victor Breno Pedrosa • \\ Adriana de Farias Jucá • André Gustavo Leão • \\ Antonia Kécya França Moita
}

Accepted: 10 January 2013 / Published online: 24 January 2013

(C) Springer Science+Business Media Dordrecht 2013 multivariate approach revealed some information that cannot be neglected in order to ensure a more detailed assessment.

Keywords Beef $\cdot$ Bovine $\cdot$ Correlations $\cdot$ Growth $\cdot$ Principal components

\section{Introduction}

The Angus breed has a significant role in beef production; therefore, it is essential to develop studies to assess its performance in different countries. In Brazil, the Angus carcass quality has been evaluated by ultrasound images of the longissimus muscle between the 12th and 13th ribs, in order to estimate its area and fat thickness. Additionally, visual precocity, muscling, conformation, skeletal, and breed scores have been used to provide more important information for the selection of animals in breeding programs because according to Faria et al. (2009) and Koury Filho et al. (2010), these scores have moderate heritability. Other studies found low heritability for visual scores such as Queiroz et al. (2011) studying Brangus cattle, but due to genetic correlation with traditional measures of weights at birth, at weaning, and at yearling, they can adequately guide the selection process for improving productivity. However, the large number of traits mentioned above should be better evaluated by multivariate methods because only multi-trait approach is able to simultaneously evaluate all traits such as showed in Insausti et al. (2008).

Another important aspect lies in the identification of fixed effects and covariates to be adjusted in statistical models in order to reduce deviations caused by environmental factors 
when genetic parameters are estimated. Age and gender are factors known to affect animal performance, but other effects such as mother's weight are poorly studied. Feeding condition has been extensively studied, but only in experimental environment with small sample size. Few results are known in commercial farms with large sample. Thus, the objectives were to: evaluate 16 phenotypic traits in 1,645 Angus cattle; analyze the correlation between the traits by univariate and multivariate approaches; and to test the effects of gender, animal's age, mother's weight at weaning, and feeding conditions on visual scores, weights, and carcass ultrasound images.

\section{Material and methods}

\section{Animals}

A total of 1,645 Angus, males and females, with age at weaning of 180.6 days (30.8 days of standard deviation) and age at yearling of 500.9 days (78.5 days of standard deviation) were evaluated. All animals were grouped according to feeding condition in: non-supplemented animals grazing native pasture; supplemented animals grazing native pasture; non-supplemented animals grazing cultivated pasture; supplemented animals grazing cultivated pasture; and animals feeding in feedlot.

\section{Visual scores}

Visual conformation scores at weaning and yearling (CSY), visual precocity scores at weaning and yearling, visual muscling scores at weaning and yearling, visual skeletal score at weaning and yearling (SSY) and the visual breed scores at weaning and yearling (BSY) were obtained according to PROMEBO guidelines (Campos 2011). The conformation visual score assesses the amount of meat on carcass; precocity visual score assesses degree finishing of carcass in animals that have appropriate slaughter weight; muscling visual score assesses the development of muscling mass in points as forearm, shoulder, loin, rump, and especially along the posterior; skeletal visual score assesses length and height of the animal; and breed visual score assesses whether the animal has a racial pattern in accordance with the rules of their respective breed association. For all visual score evaluations, animals of the same management group were observed by a trained professional that used a scale of visual scores ranging from 1 to 5 .

\section{Weight and carcass traits}

Weight at birth, weight adjusted to 205 days of age (W205weaning), and weight adjusted to 550 days of age (W550yearling); rib eye area at weaning (REAW) and at yearling
(REAY); and fat thickness at yearling (FT) obtained by ultrasound between the 12th and 13th ribs were assessed and carcass traits were evaluated.

\section{Statistical analysis}

Descriptive statistical analyses were performed for each gender. Feeding condition and gender were fixed effects and mother's weight at weaning and animal's age were covariates evaluated in analysis of variance. Maximum error type I of $5 \%$ was accepted and when analysis of variance was significant $(P<0.05)$, then Tukey's test was applied to assess difference between five feeding conditions. Pearson's correlation coefficients among all traits, two by two, were also estimated. Principal component analysis was carried out using the correlation matrix to obtain eigenvalues and eigenvectors according to Kahttree and Naik (2000), and minimum cumulative percentage of $80 \%$ was used to select principal components. All statistical analysis was carried out using the Statistical Analysis System (SAS Institute Inc 2004).

\section{Results}

Ultrasound carcass images and live weights

There was an important effect of gender on growth and carcass traits (Table 1). Rib eye area at weaning and yearling was slightly greater in males than in females, but, on the other hand, females presented larger fat thickness at yearling. Males also were heavier than females at the three ages considered. Dam weight at weaning and the animal's age had also significant effect on the weights at birth, at weaning, and at yearling (data not showed) and linear model was the better fit. Maximum and minimum values as well as standard deviation showed large range and variation in the animals for some traits, for instance fat thickness, and a possible reason for this range and variation is the farm feed condition.

The animals raised on feedlot as much as on cultivated pasture with supplement presented carcasses with higher fat thickness and rib eye area at yearling than animals on native pasture (Table 2). Supplemented animals grazing native pasture gained $46.4 \mathrm{~kg}$ (205 days) and $64.5 \mathrm{~kg}$ (550 days) more than non-supplemented animals grazing native pasture. While supplemented animals grazing cultivated pasture gained $37.3 \mathrm{~kg}$ (205 days) and $114.9 \mathrm{~kg}$ (550 days) more than non-supplemented animals grazing cultivated pasture.

Visual scores

For visual scores, gender effect was significant only for precocity at weaning. However, dam weight at weaning, animal's age, and feeding condition were very important 
Table 1 Effect of gender on rib eye area (in square centimeter), fat thickness (in millimeter), and body weights (in kilogram)

$N$ sample size, $L S M$ least square means (different letters in the column indicate significant effect $(P<0.05)$ of gender by ANOVA $F$ test), $S D$ standard deviation

\begin{tabular}{llll}
\hline Traits & $N$ & LSM \pm SD & Minimum and maximum values \\
\hline Rib eye area at weaning in male & 1,063 & $30.70 \mathrm{a} \pm 10.35$ & $(9.2-60.7)$ \\
Rib eye area at weaning in female & 1,056 & $28.48 \mathrm{~b} \pm 8.99$ & $(9.3-60.6)$ \\
Rib eye area at yearling in male & 719 & $46.57 \mathrm{a} \pm 13.42$ & $(20.1-90.6)$ \\
Rib eye area at yearling in female & 1,089 & $40.72 \mathrm{~b} \pm 13.17$ & $(20.0-89.3)$ \\
Fat thickness in male & 615 & $2.12 \mathrm{a} \pm 1.73$ & $(0.4-14.4)$ \\
Fat thickness in female & 1,065 & $2.61 \mathrm{~b} \pm 2.20$ & $(0.4-14.7)$ \\
Body weight at birth in male & 1,645 & $34.95 \mathrm{a} \pm 4.68$ & $(18.0-50.0)$ \\
Body weight at birth in female & 1,629 & $32.63 \mathrm{~b} \pm 4.36$ & $(14.0-50.0)$ \\
Body weight at 205 days in male & 1,586 & $184.04 \mathrm{a} \pm 44.75$ & $(68.0-414.0)$ \\
Body weight at 205 days in female & 1,569 & $174.53 \mathrm{~b} \pm 39.20$ & $(77.0-402.0)$ \\
Body weight at 550 days in male & 967 & $350.21 \mathrm{a} \pm 82.46$ & $(202.0-653.0)$ \\
Body weight at 550 days in female & 1,107 & $306.59 \mathrm{~b} \pm 73.39$ & $(189.0-653.0)$ \\
\hline
\end{tabular}

effects $(P<0.01)$ to evaluate all visual score in this study. Dam's weight showed a better fit when linear model was chosen, while animal's age was better adjusted with linear model for visual scores at weaning and quadratic model for visual scores at yearling. Higher scores at weaning were found for animals that grazed native pasture in comparison to animals that grazed cultivated pasture (Table 3 ). However, at yearling, the higher visual scores were observed for animals grazing cultivated pasture. In the postweaning period, the continuous supply of grass from cultivated pastures enables better visual scores than those obtained for animals grazing native pasture. Supplemented animals that grazed native pasture had all visual scores higher than non-supplemented animals that were fed with the same type of pasture. However, on cultivated pasture condition, supplementation improved visual scores only at weaning.

\section{Coefficient of correlation between the traits}

All Pearson's correlation coefficients were highly significant ( $P$ value $<0.0001)$, except between body weight at weaning and fat thickness at yearling $(r=0.04)$. Correlations between carcass traits were moderate and positive. Thus, animals with higher rib eye area also presented the greatest fat thickness. Correlation between visual scores ranged from moderate to high level at weaning and at yearling. The breed scores had high correlation with precocity, musculature, skeletal, and conformation at weaning $(>0.74)$ and yearling $(>0.68)$. Correlation coefficients among visual scores and weight at 205 and 550 days were of moderate magnitude and the largest coefficient (0.73) was among precocity at weaning and W205. The W205 and W550 also showed positive correlations with carcass measures; the largest (0.81) estimation was between W550 and rib eye area at
Table 2 Effect of feeding condition on least square means of body weight and carcass traits

${ }^{a}$ Different letters in the column indicate significant effect $(P<$ $0.05)$ of feeding condition by Tukey's test

${ }^{\mathrm{b}} \mathrm{Rib}$ eye area is not evaluated before feedlot period

${ }^{\mathrm{c}}$ All $P$ values in $F$ test for feeding condition in ANOVA were $<0.05$

\begin{tabular}{lllc}
\hline Feeding condition $^{\mathrm{a}, \mathrm{c}}$ & $\begin{array}{l}\text { Rib eye area at } \\
\text { yearling }\end{array}$ & Fat thickness & $\begin{array}{l}\text { Rib eye area } \\
\text { at weaning }\end{array}$ \\
\hline Animals grazing native pasture & $41.41 \mathrm{a}$ & $1.77 \mathrm{a}$ & $27.08 \mathrm{a}$ \\
Animals grazing native pasture and supplemented & $52.14 \mathrm{~b}$ & $3.26 \mathrm{~b}$ & $41.04 \mathrm{~b}$ \\
Animals grazing cultivated pasture and supplemented & $69.92 \mathrm{c}$ & $5.96 \mathrm{c}$ & $40.47 \mathrm{~b}$ \\
Feedlot & $63.32 \mathrm{c}$ & $5.93 \mathrm{c}$ & - \\
Root mean square error in ANOVA & 9.08 & 0.66 & 7.52 \\
Feeding condition & Body weight & Body weight & Body weight \\
& at 550 days & at 250 days & at birth \\
Animals grazing native pasture & $309.76 \mathrm{a}$ & $174.46 \mathrm{a}$ & $33.94 \mathrm{a}$ \\
Animals grazing cultivated pasture & $307.43 \mathrm{a}$ & $164.26 \mathrm{a}$ & $34.06 \mathrm{ab}$ \\
Animals grazing native pasture and supplemented & $374.31 \mathrm{~b}$ & $220.82 \mathrm{c}$ & $33.72 \mathrm{a}$ \\
Animals grazing cultivated pasture and supplemented & $422.35 \mathrm{c}$ & $201.60 \mathrm{~b}$ & $34.08 \mathrm{ab}$ \\
Feedlot & $479.81 \mathrm{~d}$ & $240.51 \mathrm{~d}$ & $35.43 \mathrm{~b}$ \\
Root mean square error in ANOVA & 51.51 & 33.47 & 4.14 \\
\hline
\end{tabular}


Table 3 Effect of feeding condition on least square means of visual scores
All $P$ values of $F$ test in ANOVA for feeding condition were $<0.0001$

${ }^{a}$ Different letters in the same line indicate significant difference by Tukey's test $(P<0.05)$

\begin{tabular}{|c|c|c|c|c|c|c|}
\hline Traits $^{\mathrm{a}}$ & $\begin{array}{l}\text { Native } \\
\text { pasture }\end{array}$ & $\begin{array}{l}\text { Cultivated } \\
\text { pasture }\end{array}$ & $\begin{array}{l}\text { Native pasture }+ \\
\text { supplementation }\end{array}$ & $\begin{array}{l}\text { Cultivated pasture } \\
+ \text { supplementation }\end{array}$ & Feedlot & $\begin{array}{l}\text { Root mean } \\
\text { square error }\end{array}$ \\
\hline \multicolumn{7}{|l|}{ Weaning } \\
\hline Conformation scores & $3.59 \mathrm{a}$ & $2.77 \mathrm{~b}$ & $4.50 \mathrm{c}$ & $3.72 \mathrm{a}$ & $4.47 \mathrm{c}$ & 0.76 \\
\hline Precocity scores & $3.38 \mathrm{a}$ & $2.42 \mathrm{~b}$ & $4.40 \mathrm{c}$ & $3.88 \mathrm{~d}$ & $4.24 \mathrm{c}$ & 0.72 \\
\hline Muscling scores & $3.46 \mathrm{a}$ & $2.37 \mathrm{~b}$ & $4.44 \mathrm{c}$ & $3.96 \mathrm{~d}$ & $4.37 \mathrm{c}$ & 0.77 \\
\hline Skeletal score & $3.42 \mathrm{a}$ & $3.01 \mathrm{~b}$ & $4.32 \mathrm{~d}$ & $3.95 \mathrm{c}$ & $4.21 \mathrm{~cd}$ & 0.69 \\
\hline Breed scores & $3.68 \mathrm{a}$ & $3.11 \mathrm{~b}$ & $4.59 \mathrm{~d}$ & $4.26 \mathrm{c}$ & $4.58 \mathrm{~cd}$ & 0.77 \\
\hline \multicolumn{7}{|l|}{ Yearling } \\
\hline Conformation scores & $3.68 \mathrm{a}$ & $4.59 \mathrm{bc}$ & $4.04 \mathrm{~b}$ & $3.63 \mathrm{a}$ & $4.81 \mathrm{c}$ & 0.66 \\
\hline Precocity scores & $3.47 \mathrm{a}$ & $4.16 \mathrm{bc}$ & $4.02 \mathrm{c}$ & $3.60 \mathrm{ac}$ & $4.64 \mathrm{~b}$ & 0.61 \\
\hline Muscling scores & $3.41 \mathrm{a}$ & $4.16 \mathrm{bc}$ & $3.97 \mathrm{c}$ & $3.33 \mathrm{ac}$ & $4.65 \mathrm{~b}$ & 0.65 \\
\hline Skeletal score & $3.53 \mathrm{a}$ & $4.05 \mathrm{~b}$ & $3.99 \mathrm{~b}$ & $3.36 \mathrm{ab}$ & $4.65 \mathrm{c}$ & 0.60 \\
\hline Breed scores & $3.72 \mathrm{a}$ & $4.66 \mathrm{bc}$ & $4.13 \mathrm{c}$ & $3.79 \mathrm{ac}$ & $4.81 \mathrm{~b}$ & 0.72 \\
\hline
\end{tabular}

yearling. Finally, visual scores showed moderate correlation coefficients with fat thickness and rib eye area.

Principal component analysis

A principal component analysis was performed to identify linear combinations that summarize the total variance of the traits in a small number of factors. Thus, it was possible to summarize $80 \%$ of the total variance of 15 traits with the four first principal components (Table 4). This finding reveals a strong correlation between the traits of this study, which leads to the need to study the eigenvectors of the correlation matrix.

Table 4 Eigenvalues and percentage of variance explained for each principal component (PC)

\begin{tabular}{llll}
\hline $\begin{array}{l}\text { Principal } \\
\text { component }\end{array}$ & Eigenvalue & $\begin{array}{l}\text { Variance (\%) } \\
\text { explained }\end{array}$ & $\begin{array}{l}\text { Cumulative } \\
\text { variance (\%) }\end{array}$ \\
\hline PC1 & 8.6095 & 57.40 & 57.40 \\
PC2 & 2.1851 & 14.57 & 71.96 \\
PC3 & 0.9949 & 6.63 & 78.60 \\
PC4 & 0.6099 & 4.07 & 82.66 \\
PC5 & 0.5024 & 3.35 & 86.01 \\
PC6 & 0.3813 & 2.54 & 88.55 \\
PC7 & 0.3447 & 2.30 & 90.85 \\
PC8 & 0.3105 & 2.07 & 92.92 \\
PC9 & 0.2557 & 1.70 & 94.63 \\
PC10 & 0.1811 & 1.21 & 95.83 \\
PC11 & 0.1727 & 1.15 & 96.99 \\
PC12 & 0.1454 & 0.97 & 97.95 \\
PC13 & 0.1207 & 0.80 & 98.76 \\
PC14 & 0.1063 & 0.71 & 99.47 \\
PC15 & 0.0799 & 0.53 & 100.00 \\
\hline
\end{tabular}

The first principal component had all eigenvectors very similar in magnitude, except for FT with a slightly lower coefficient (Table 5). This principal component alone explained approximately $57.4 \%$ of the total variation. The second principal component explained $14.57 \%$. The third principal component explained $6.63 \%$ of total variation and the fourth principal component explained $4.07 \%$ of total variation.

\section{Discussion}

Ultrasound carcass images and live weights

The results in Table 1 showed large range for all traits. For instance, rib eye area at weaning had a minimum value of

Table 5 Eigenvectors of the four first principal components (PC)

\begin{tabular}{lllll}
\hline Traits & PC1 & PC2 & PC3 & PC4 \\
\hline Body weight at 205 days & 0.26 & -0.21 & 0.12 & -0.30 \\
Body weight at 550 days & 0.27 & 0.17 & 0.41 & -0.08 \\
Conformation scores at weaning & 0.27 & -0.29 & -0.16 & 0.27 \\
Conformation scores at yearling & 0.25 & 0.27 & -0.44 & 0.08 \\
Precocity scores at weaning & 0.27 & -0.30 & 0.05 & -0.10 \\
Precocity scores at yearling & 0.27 & 0.25 & 0.04 & -0.33 \\
Muscling scores at weaning & 0.27 & -0.29 & -0.08 & 0.18 \\
Muscling scores at yearling & 0.26 & 0.29 & -0.23 & 0.01 \\
Skeletal scores at weaning & 0.26 & -0.30 & 0.03 & -0.08 \\
Skeletal scores at yearling & 0.26 & 0.22 & 0.01 & -0.45 \\
Breed scores at weaning & 0.27 & -0.27 & -0.13 & 0.30 \\
Breed scores at yearling & 0.25 & 0.28 & -0.44 & 0.10 \\
Rib eye area at weaning & 0.25 & -0.19 & 0.10 & -0.23 \\
Rib eye area at yearling & 0.25 & 0.23 & 0.37 & 0.22 \\
Fat thickness & 0.20 & 0.27 & 0.41 & 0.51 \\
\hline
\end{tabular}


$9.2 \mathrm{~cm}^{2}$ and maximum value of $60.69 \mathrm{~cm}^{2}$. Two possible reasons for this range are farm condition and animal age. Unlike experimental data that are assessed with rigid control of environmental conditions, here we assessed observational data of animals raised in uncontrolled farm conditions, with several feed condition and ages. This is an important factor of the present study because their results are applied to farm conditions.

The superiority of males for rib eye area (Table 1) results, as known, from the impetus of growth caused by androgenic hormones, particularly testosterone (Di Marco 1994). Females present higher fat thickness because they start the deposition of fat earlier than the males (Berg and Butterfield 1976), as a result of the early finishing growth. Males also were heavier than females at the three ages considered, which is already expected due to the sexual dimorphism in cattle.

This study showed that variation in growth and finishing also depends on the type of feed available. Diets containing higher energy levels in intensive feeding systems enable improve fat thickness deposit when compared to animals feeding diets with lower energy level. Pavan and Duckett (2008) showed that supplementation to Angus grazing improves carcass weight. However, studies such as Pavan and Duckett (2008), that assess relationship among performance and nutrition, are usually experimental, highly controlled, and use a small sample, while in the present study, hundred animals were assessed on uncontrolled farm condition.

Superior weight at yearling of animals raised in feedlot (Table 2), in comparison to other groups, cannot accurately be assigned as an effect of the feeding condition, since the animals taken to feedlot were heavier at birth and weaning, i.e., before feedlot. In general, one can say that supplementation improved the performance of grazing animals at weaning and yearling.

Dam's weight at weaning had significant linear positive effect on the weights at birth, weaning, and yearling (data not showed). Therefore, mothers who have good body condition in late lactation have heavier calves. The maternal environment can strongly influence the offspring performance; thus, keeping the cow in good body condition is a key to improve the development of their offspring.

\section{Visual scores}

The least square means for visual conformation, precocity, muscling, and skeletal scores at weaning were higher than the results obtained by Cardoso et al. (2001) with Angus at weaning, which found mean values and standard deviation of $2.92 \pm 1.10,3.09 \pm 1.08,2.97 \pm 1.06$, and $3.00 \pm 1.06$, respectively, for visual conformation, precocity, muscling, and skeletal scores. Araújo et al. (2010), evaluating crossbreed
Angus $\times$ Nellore at weaning, found mean values and standard deviation of $3.24 \pm 0.95,3.19 \pm 0.94,3.28 \pm 0.97$, respectively, for visual conformation, precocity, and muscling scores. However, Cardoso et al. (2001) and Araújo et al. (2010) did not consider animal feeding conditions in their models, and one can observe in the Table 3 that feeding condition was a very important effect for visual score evaluation at weaning and yearling.

The visual scores at weaning were larger in animal grazing native pasture than animal grazing cultivated pasture. At weaning, it is expected that visual scores depend more of the cow's milk than the grazing pasture itself, but perhaps the milk quality from cows grazing native pasture is more nutritious than milk from cows grazing cultivated pasture. Native pasture is characterized by greater diversity of forage. Thus, it is possible that native pasture has more forages with great protein rates than cultivated pasture. In the postweaning, the supply of grass of cultivated pastures enables better visual scores than those obtained for animals grazing native pasture, where the supply of grass may vary widely throughout the year.

Evaluating effects of supplementation on animal performance are objective of several studies such as Blanco et al. (2008), and there is a consensus that pre-weaning supplementation is very important for calves' development. Therefore, for animals grazing cultivated pasture, the supplementation seems to be more important at pre-weaning period, while for animals grazing native pasture, the supplementation is important at pre- and post-weaning periods.

\section{Coefficient of correlation between the traits}

Moderate magnitude of correlations between REAW and REAY indicates that its evaluation must be carried out at weaning and yearling because one cannot guarantee that animals with higher REAW also will be higher for REAY. Fat thickness was evaluated at weaning, but many animals had not enough fat for accurate measurement by ultrasound image.

Three important pieces of information can be drawn from the correlation between visual scores. First, the breed scores had high correlation with precocity, musculature, skeletal, and conformation which leads to the conclusion that a special attention should be given to the breed type in order to improve economic traits such as precocity. Second, high correlation coefficients between the scores of precocity, muscling, and skeletal indicate that the largest animals are also those with greater muscling development and higher precocity. Conceptually, this result reveals an error in the method of assessing precocity, since it is difficult to have larger and more muscling animals and also have early finishing fat. Third, correlations among visual scores at weaning and the same visual score at yearling indicate that the 
evaluation at weaning possibly is not a good measure to predict the same trait at yearling. There is great controversy in the literature regarding the magnitude of these correlations. For example, Koury Filho et al. (2010) observed high correlations when the same score was assessed at weaning and yearling, in Nellore cattle. However, Faria et al. (2009), also with the Nellore, observed low correlation between visual scores measured at weaning and post-weaning. Therefore, when possible, visual score assessment at weaning and yearling must be performed.

For weights, four important pieces of information were obtained. First, the lowest correlation coefficients observed between birth weight and other traits can be explained by low variation in birth weight (Table 1). Second, animals with larger W205 may also be heavier at 550 days of age because of the correlation of 0.58 , but this moderate coefficient reveals that it is important to assess weights at weaning and yearling. Third, animals with large W205 were also those who had higher scores for precocity at weaning (correlation of 0.73). Again, there is an inconsistency between precocity and weight because the correlation coefficient of fat thickness with W205 (0.41) and with precocity at weaning (0.37) is low. Finally, animals with large W550 were also those with greater development of the rib eye area at yearling (0.81). Now, the correlations between W550 with precocity at yearling $(0.65)$ and with fat thickness $(0.62)$ are closer, which makes more sense than at weaning. These results showed that is difficult to understand the complex correlation between the different traits with bivariate approach.

\section{Principal component analysis}

Multivariate approach is useful to explain the complex variation of several traits in few canonical variables. In the present study, with only four principal components, it was possible to explain more than $80 \%$ of total variance. The analyses of the principal components showed that the first principal component had all eigenvectors very similar in magnitude (Table 5). Thus, no trait alone had great importance for variation of this principal component. The total variation of this principal component demonstrated its great importance to the animals under study and showed a strong relationship between all traits. Animals with large score for this component have large value for all traits here assessed.

The second principal component reveals important information, since all the eigenvectors for visual scores at weaning were positive, while eigenvectors for visual scores at yearling were negative. Thus, animals with high values for this principal component were characterized by higher values of visual scores at yearling and lower visual scores at weaning. Similar results were observed to W205, W550, REAW, and REAY.
The magnitude of the third principal component depended mainly on W550, CSY, BSY, FT, and REAY because they demonstrated to be associated with larger eigenvectors in absolute value. Therefore, higher scores for this principal component were found by animals that had higher value of W550, REAY, and FT and lower value for CSY and BSY. Thus, selection of animals with this component cannot only reduce the scores for conformation and breed at yearling, but also improves values for W550, REAY, and FT.

The fourth principal component had the highest eigenvectors associated to SSY and FT. Thus, animals with higher values for this principal component were those with low scores for skeletal at yearling and greater fat thickness at yearling. This finding is expected since animals with a high score for body skeletal are usually later in fat deposition. Thus, the fourth principal component could be used to identify animals with large precocity.

Briefly, studies such as the Koury Filho et al. (2010) and Faria et al. (2009) also examined correlations between visual precocity, muscling, and conformation scores, but in those researches, a multivariate approach was not considered. In the present study, significant relationships between traits are found, which cannot be observed in a usual univariate approach. Thus, multivariate approach reveals some information that cannot be neglected in order to ensure a more detailed assessment. Other conclusions are that gender and feeding conditions are very significant for several traits here studied, but not for visual scores, and animal's age and mother's weight at weaning influenced many traits and must be appropriately adjusted in the statistical models. Not adjusting those factors in the statistical model can lead to inaccurate estimates of parameters.

\section{References}

Araújo, R.O., Rorato, P.R.N.; Weber, T., Everling, D.M., Lopes, J.S., Dornelles, M.A. 2010 Genetic parameters and phenotypic and genetic trends for weight at weaning and visual scores during this phase estimated for Angus-Nellore crossbred young bulls. Revista Brasileira de Zootecnia 39, 2398-2408.

Berg, R.T., Butterfield, R.M., 1976. New concepts of cattle growth. Sydney University Press, Sydney, Australia.

Blanco, M., Villalba, D., Ripoll, G., Sauerwein, H., Casasús, I., 2008. Effects of pre-weaning concentrate feeding on calf performance, carcass and meat quality of autumn-born bull calves weaned at 90 or 150 days of age. Animal 2, 779-789.

Campos, L., 2011. PROMEBO - Programa de Melhoramento de Bovinos de Carne. Retrieved December, 29, 2011, from http:// www.promebo.com.br/Manual.pdf

Cardoso, F. F., Cardellino, R.A., Campos, L.T. 2001 Fatores Ambientais sobre Escores de Avaliação Visual à Desmama em Bezerros Angus Criados no Rio Grande do Sul. Revista Brasileira de Zootecnia 30, 318-325.

Di Marco, O.N., 1994. Crecimiento y respuesta animal. AAPA, Balcarce, Argentina. 
Faria, C.U., Magnabosco, C.U., Albuquerque, L.G., Bezerra, L.A.F., Lobo, R.B., 2009. Avaliação genética de características de escores visuais de bovinos da raça Nelore da desmama até a maturidade. Revista Brasileira de Zootecnia 38,1191-1200.

Insausti, K., Beriain, M.J., Lizaso, G., Carr, T.R., Purroy, A., 2008. Multivariate study of different beef quality traits from local Spanish cattle breeds. Animal, 2, 447-458.

Kahttree, R., Naik, D.N., 2000. Multivariate data reduction and discrimination with SAS ${ }^{\circledR}$ software. SAS Institute Inc. North Carolina, USA.

Koury Filho, W., Albuquerque, 1.G., Forni, S., Silva, J.A.V., Yokoo, M.J., Alencar, M.M., 2010. Estimativas de parâmetros genéticos para os escores visuais e suas associações com peso corporal em bovinos de corte. Revista Brasileira de Zootecnia 39, 1015-1022.

Pavan, E., Duckett, S.K., 2008. Corn oil or corn grain supplementation to steers grazing endophyte-free tall fescue. I. Effects on in vivo digestibility, performance, and carcass quality. Journal of Animal Science 86, 3215-3223.

Queiroz, S.A., Oliveira, J.A., Costa, G.Z., Fries, L.A., 2011. Estimates of genetic parameters for visual scores and daily weight gain in Brangus animals. Animal, 5, 838-843.

SAS Institute Inc 2004. SAS/STAT User's Guide: version 9.1. SAS Institute Inc., North Carolina, USA. 